\title{
sciendo
}

\section{Bioeconomy's sectors and strategies in Central and Eastern European countries. A literature review}

\author{
Mugur Victor Constantin IUREȘ \\ University of Craiova, Doctoral School of Economics, Faculty of Economics and Business \\ Administration \\ iuresv@gmail.com
}

\begin{abstract}
This paper aims to identify and review the most important and topical scientific papers that deal with the strategies that the countries of Central and Eastern Europe apply in the bioeconomic field. In the context of a special attention paid to this sector by the policymakers, seen through the adoption of The Bioeconomy Strategy, in 2012, by the European Union and updated in 2018, it is natural to ask what is the current state of knowledge in this field? This paper treats with the sectors enclosed in this field, from agriculture to biofuels and from paper production to biopharmaceuticals, based on the scientific literature underpinnings, given that this development sector is an emerging one and the ampleness of the scientific works being limited. The methodology of this paper comprises the literature review of the main results obtained this far, in order to accomplish the foundation for further research.
\end{abstract}

Keywords: bioeconomy, Central and Eastern European countries, sectors, strategies.

\section{Introduction}

According to the United Nations (UN) 2019 report regarding the population it shows that at present there is a population of 7.7 billion, and by 2030 it will reach a population of 8.5 billion, and by 2050 there will be 9.7 billion. Forecasts show that in this situation by 2100 there will be 10.9 billion people on Earth. Trends in population size and age composition are mostly formed by fertility and mortality rates that have declined around the globe almost evenly (UN, 2019). Global migration has also become a major determinant of population change in several countries. This only results in faster consumption of resources.

In this work we will discuss about the identified sectors and strategies in the field of bioeconomy in the central and eastern area of the European Union. To do this we will conduct a review of the specialized literature and will also conduct a brief review of the policies in the field of bioeconomy in the countries that make up this group (Estonia, Latvia, Lithuania, Poland, Czech Republic, Slovakia, Hungary, Romania, Bulgaria, Slovenia, Croatia).

In the context of the European Union and of the importance granted by the EU to the field of Bioeconomy. We cannot forget the bioeconomy strategy adopted in 2012 which, in contrast to the OECD's 2009 strategy (OECD, 2009), which focuses on biotechnology, the European Union's strategy is aimed at all sectors of the bioeconomy: Agriculture, Bio-based chemicals and materials, Bio-based textiles, Bioenergy, Biotechnology, Fisheries and aquaculture, Food, Forestry, Organic waste, Pulp paper wood products and furniture (EC, 2012). In 2018 the European Union has adopted a revised strategy and adapted to maintain its competitiveness with a constantly changing environment, this strategy is based on three pillars: Investments in research, innovation and skills; Reinforced policy interaction and stakeholder engagement; and Enhancement of markets and competitiveness (EC, 2018).

The field of bioeconomic enjoys increasing attention as regards policy makers who place an interest on the potential it has in creating a sustainable and circular economy. Entrepreneurs 
want to benefit from this sector, both due to the continuous and accelerated development of the Domain and due to the decreasing costs due to the subsidies granted for Research and Development investments (against the backdrop of subsidies, rapid development and competition in the various sectors of the bioeconomy make this area more and more advantageous for entrepreneurs, and this in conjunction with social responsibility). In addition to social responsibility, the fact that the Bioeconomy sector is revered both entrepreneurs and policy makers has made this sector a priority for EU Member States.

With 2012 and what would be the first EU bioeconomy strategy, researchers' interest in this area has grown exponentially according to the study published in 2016. This study carried out a bibliometric analysis regarding the number of works published between 2005-2014, it was 453 of which 203 in 2005-2011 and 250 in 2012-2014(Anon, 2016). In the context of the importance attributed to the bioeconomy and the strategies drawn up at EU - CEE level, the general objective of this paper is to investigate the literature of speciation to determine the current state of knowledge as well as to discover new levels of research. Starting from the attention that both entrepreneurs, policy makers and researchers give to the field of Bioeconomics, as well as the importance, it has, in developing a sustainable and circular economy, we see the novelty of this topic (Rizo, 2018).

This study consists of reviewing the literature in the field of bioeconomy with a specific focus in the European Union - the CEE MS from the point of view of economic growth. Limiting the study to the EU will allow a more detailed analysis.

The keywords for the literature search were supposed to cover the three areas of interest in the study's purpose. The keywords that ware used: bioeconomy, European Union and economic development, Central and Eastern Europe.

\section{Literature review}

\section{Concept}

Early work in bioeconomy was conducted by Nicolas Georgescu-Rogen whom firstly used the term to justify the biological roots to all economic process (Georgescu-Roegen, 1977). Moreover, in an early work he defined economic entropy is a complex process of continuous and irremediable degradation of the potential of existing resources, as well as the creation of a disorganization. It is a term contained in the thermo-economic theory. Entropic degradation is a process that takes place over time, at a greater or lesser speed, making visible the reduction of resources. While in nature the entropy process occurs by itself, the economic process is directly dependent on the human activity in which the consumption of goods entails entropy, that is, degradation, through the production of waste and through the dysfunctions that occur in this process. Nicolae GeorgescuRoegen stated that "The economic process is clearly entropic and not mechanistic. And because the law of entropy dominates all material transformations, this process develops in an irreversible way. The depletion of resources cannot be controlled and much of the waste remains unused. This simple statement contains the germs of the "shortage" seen from a global ecological perspective "(Georgescu-Roegen, 1971)

Concept became popular by launching the Bioeconomy Strategy in 2012, at the initiative of the European Commission (EC). The EC strategy defined Bioeconomic as "renewable energy production, biological resources and the transformation of these resources and waste streams into value-added products, such as food, feed [and] bio-based products, as well as bioenergy" (EC, 2012) 
Another key advocate in the field of bioeconomy was the United Nations (UN), which in 2015 developed 17 SDGs - Sustainable Development Goals - goals to be achieved by 2030 (UN, 2015).In the paper Analysis of the relations between circular economy and sustainable development goals - (Rodriguez-Anton, 2019) verifies the correlation between circular economy and the SDGs - the statement that they are correlated verifies for fully for 4 SDGs $(8,9,11,12)$ while two of them are partially accepted $(13,14)$ and two of them are rejected as there is no correlation. The SDGs are selected based on community legislation and the author implies that there can be a strong correlation between "the CE and SDGs 2, 3, 5, and 16, which do not appear collected, specifically, in the community legislation." (Rodriguez-Anton, 2019)

This strategy was updated at the initiative of the President of the European Commission Jean Claude Junker, in 2018, the reason for the update being to keep the strategy competitive, through a set of 14 concrete actions. These actions reflect the conclusions of the 2017 analysis of the strategy and aim to create a sustainable and circular economy. The 14 actions are divided into three main areas of action. (EC, 2018)

"Documenting the bioeconomy is a challenge for science and research because official statistics only report on traditional sectors with no distinction between synthetic and bio-based production (e.g. manufacture of synthetic textile vs bio-based textile). Therefore, indicators for the bioeconomy are estimated based on a combination of multiple sources." (Ronzon et al., 2015, p. 4)

From Ronzon et al. although agriculture, at the level of 2013, employs most of the people in the field of bioeconomy, 56 percent at the level of the whole EU, it obtains $19 \%$ of the turnover of the whole sector. at the same time $55 \%$ Of the turnover of the whole sector was represented by the field of beverage and the Tobacco Industry, which represents $25 \%$ of the total number of people employed in the bioeconomy sector.

Table 1: Bioeconomy's features within the EUMS CEE

\begin{tabular}{|c|c|c|}
\hline No. & Characteristics & Countries \\
\hline 1. & $\begin{array}{l}\text { Bioeconomy in which agriculture } \\
\text { employees predominate }\end{array}$ & $\begin{array}{l}\text { Romania, Poland, Slovenia, } \\
\text { Croatia - with more than } 60 \% \text { of } \\
\text { employees in the bioeconomy } \\
\text { sector. }\end{array}$ \\
\hline 2. & $\begin{array}{l}\text { Bioeconomy dominated by the } \\
\text { agro-food industry and bio-chemical } \\
\text { industries (based on the chemical, } \\
\text { pharmaceutical and plastic industries) }\end{array}$ & $\begin{array}{l}\text { No EU MS CEE - can be } \\
\text { categorized in this section }\end{array}$ \\
\hline 3. & $\begin{array}{l}\text { Bioeconomy where the turnover is } \\
\text { mainly generated by the forestry industry }\end{array}$ & $\begin{array}{l}\text { Latvia and Estonia - with } \\
\text { more than } 40 \% \text { of the bioeconomy } \\
\text { turnover. }\end{array}$ \\
\hline 4. & Non-specialized bioeconomy & $\begin{array}{l}\text { Bulgaria, Hungary, } \\
\text { Slovakia, the Czech Republic and } \\
\text { Lithuania, which presents a } \\
\text { combination of several bioeconomy } \\
\text { sectors. }\end{array}$ \\
\hline
\end{tabular}

Source: Ronzon et al., 2015, p. 4 
Renewable energy have raised concerns about the adequacy and sustainability of forest biomass resources. Reliable and understandable estimates of biomass capacity and future demand are needed for policy decision-making, but the available findings differ widely among studies (Hänninen, 2018)

\section{Strategies applied}

PICBE $\mid 86$

In this year, 8 years of existence of the European Union's bioeconomy strategy have been completed, which has enjoyed triumphs in several areas, such as many member states and regions already develop their own roadmaps and establish strategies Theories of intelligent specialization, that is to say, established that the bioeconomy will unravel a more sustainable present and future for Europe and its inhabitants (Dupont-Inglis et al., 2018) .The European Commission with the purpose of marking a beginning of The bioeconomy has proposed several strategies to build a sustainable economy related to biodiversity as a great opportunity to discuss various problems such as food security, dependence on fossil resources, depletion of natural resources and the enormous climate change, highlighting the reasonable and sustainable use of natural resources and the environment (Scarlat et al., 2015). Likewise, it recognizes potential dangers that should not be overlooked, such as: 1) competitiveness between food supply and bio-mass manufacturing, 2) reindustrialization and monopolies of agri-food production, 3) mass exploitation of natural resources and decrease in biodiversity and 4) damage to consumer belief (Imbert, et al. 2017).

In 2002, the European Commission confirmed that biotechnology and life sciences are among the most competent and powerful technologies to contribute to the achievement of the objectives of the Lisaboa Agenda, three years later in the In 2005, an international presentation was made on the bioeconomy based on knowledge, in 2007 the presentation continued but this time marking an important milestone where the scenarios on the European bioeconomy for the next 20 years were presented. Thanks to these conferences, bio-economics was given great importance in European political circles (McCormick et al., 2013).

For 2012, the European Union exhibited its initial bioeconomy strategy aimed at perfecting new technological processes, boosting markets and competition and encouraging a close cooperation between political leaders and stakeholders (Fund, et al., 2015). In the same year the European Commission, based on the conclusions of the reports and consultations of the interested parties, disseminated a document that combines strategies and action plans called "Innovating for sustainable growth: a bioeconomy for Europe", Its main goals are to provide the necessary guidelines for innovation and research agendas in the areas of bioeconomy, support for a more prosperous political environment and seek ways for a more innovative, competitive and effective European community in the use of resources (De Besi et al., 2015). The European Commission points out that the bioeconomy is a strategic element for smart and ecological growth and development; hence, for example, the European bioeconomy occupies a market dimension of more than 2 billion euros and provides 22 million jobs in sectors such as bioenergy, agriculture, food, forestry and chemical products, which mean $9 \%$ of the total labor power of the European Union (McCormick et al., 2013).

The political strategies established by the European Commission (EC) and the Organization for Economic Cooperation and Development (OECD) underline the importance that the bioeconomy and the change of humanity to be dependent on fossil resources, are occupied an important place in the international political and economic space as well as the European one. These strategies have caused several European countries, regions and industries to adopt and 
develop new skills, which expose their purposes and visions in the application of a bioeconomy in Europe (De Besi et al., 2015). Thanks to the intervention of The European Commission within the bioeconomy in Europe included the formation of the European bioeconomy panel, whose main objective is to address the contradictions within the political margin of the European Union. The bioeconomy panel seeks to integrate policies at the national and regional level, proposing to establish bioeconomy panels at interdepartmental and regional levels to extend collaboration and coherence (De Besi et al., 2015). Integration is based on 3 key pillars: 1) research funding, innovation and skills, 2) strengthening of political interaction and the agreement of the Stakeholders and 3) market progress and competition in bioeconomic sectors (De Besi et al., 2015). Although most European countries focus on developing research strategies and Innovation includes bioeconomy within them, expanding green or blue growth strategies and incorporating strategies oriented in the circular economy. For example, one of the policies that the European Union changed is related to biofuels, they decided to support second-generation biofuels which are made from lignocellulosic biomass, that these biofuels are formed from planting or crop residues in marginal lands (Lewandowski, 2015).

The countries from CEE have already taken action in forming Central-Eastern European Initiative for Knowledge-based Agriculture, Aquaculture and Forestry in the Bioeconomy (BIOEAST) "The shift resulted to the birth of Central-Eastern European Initiative for Knowledge-based Agriculture, Aquaculture and Forestry in the Bioeconomy (BIOEAST). An initiative that could offer shared strategic research and innovation framework for working towards sustainable bioeconomy in the Central and Eastern European (CEE) countries." BIOEAST

\section{Sectors enclosed}

A research conducted in 2019, focusing on the importance granted to bioeconomy credentials, divided the member states of the EU into two clusters. - the second format of the new states, EU$13 \mathrm{MS}$, this being mainly CEE countries, the study being carried out on the comparison of the influence of intellectual capital. The paper has shown that tertiary education plays an important role in influencing bioeconomy coordinates. This effect is more pronounced in the group E.U.-13 M.S. The financial support granted to encourage research and development has generated a positive result in both clusters, this fact being observable by increasing the number of patents.

In this part we will take the countrys that have publications about the state of bioeconomy sector and strategys country (Estonia, Latvia, Lithuania, Poland, Romania,) and detaliate about what is tha current state of knowledge:

There is a different distribution regarding the Baltic States, regarding the production, consumption and trade of biobased resources, in Estonia, it is one in three, which are used in the national production, compared to the other Baltic states that use in the production. national 50\% of the resources. And as a consumption of bio resources, only 19\% are used in Estonia. In the case of Estonia production-based land footprint is even bigger than the entire territory of the country and Estonia is a donor of bioeconomy resources to other countries. Estonia should consider better resource management to produce greater added value in bioeconomic activities at national level 
In Latvia, half of the resources used in domestic production are bio resources, and consumption-based resource use is at the level of $1 / 3$, in terms of bio resources. Latvia and Lithuania in terms of land footprint almost achieved the country territory capacity

In Lithuania, half of the resources used in domestic production are bio resources, and consumption-based resource use is at the level of $1 / 3$, in terms of bio resources. Latvia and Lithuania in terms of land footprint almost achieved the country territory capacity. Regarding Lithuania, the highest share of the produced land footprint was consumed domestically. The land footprint efficiency was the highest. Land footprint efficiency was the lowest from the Baltic states.

In Romania, an INCDSB project, funded by the government, aims to "substantiate, elaborate, finalize and communicate the priorities for the development of bioeconomy in Romania for the period 2016-2030 by (i) assessing the $R \& D$ potential and the industrial potential in the bioeconomic field; (ii) identifying priorities for the integration of national economic sub-systems into European bio-economic development, and (iii) establishing the main actions needed to achieve identified priorities ". This year also ends the project Rural Development Program, a program adopted by the European Commission in 2015, which involves measures and properties to invest EUR 9.5 B. This project for Romania, would mean the target of 300 projects funded with up to more than 27000 jobs created.

Poland is among the creators of the Visegrad accumulate (V4), at the side Czech Republic, Slovakia and Hungary. The group was as of late broadened to consolidate Bulgaria, Romania, Croatia, Slovenia and Estonia (V4+). Priests of Cultivation of the V4+ have concurred in 2016 on setting up a common movement, named Central-Eastern European Action for Knowledgebased Cultivating, Aquaculture and Officer benefit inside the Bioeconomy (acronym: BIOEAST), indicating at setting up a common strategy on bioeconomy and at bracing the joins between the included divisions over the borders. BIOEAST recognizes two associated holes inside the Central Eastern Europe macro-region: opening of fabulousness in low performing examine, headway and improvement areas, and bringing specific ask almost subjects imperative to the CEE macro-region in Horizon 2020 work programs (Ronzon et al, 2018).

\section{Conclusion}

Bioeconomy research, motivated by the need for a more efficient and sustainable way of using the resources of our world, reveals that it has great potential to combine political, social and environmental benefits. Nevertheless, most bioeconomy products are not profitable or only available in a prototype or experimental version because most of them are not yet commercially attractive.

The term bioeconomy is still very heterogeneous, but the efforts that the EU is making in this direction in terms of bringing the research, innovation and sustainable entrepreneurship in full play a huge awareness role for hundreds.

For the coutrys like the CEE group Bioeconomy should maniefst as a oportunity to become more developed, given theier tradition and agricultural heritage and that should bridge a the gape between the Wester Europe, the deveoped part of the continent, and CEE statets that are undergoing development.

The countrys from CEE, are still behinnde and loosing momentum in terms of acting, given the fact that they didn't that are still in early stagies in development of a consolidate strategy of 
common suport in term of reserch and inovation. A cleear sign of this is the lack of scientific literature in this domain for certain countrys (Hungary, Bulgary, Czech Republic, Slovenia, Slovakia and Croatia)

Sustainable technology has played a key role in driving activity into new sustainabledevelopment projects, adopting its separate but interrelated ecological, economic and socialfoundations. The increasing pace of changes in the environment and innovation has a significantimpact on all organisations, including companies. In today complex economic environment,unpredictable, companies and organizations are seeking new ways to achieve their strategicobjectives to ensure long-term success.

I firmly believe that this is the moment when there must be a change in strategy in the needles regarding the way we do things, given the speed with which we have come to consume resources and I think that if we do not make a change in the present, the near future may be too late to change anything radically.

\section{References}

Anghel I., Siminică M., Cristea M., Noja G.G.\& Sichigea M. (2019) Bioeconomy credentials and intellectual capital: a comparative modelling approach for the E.U.-13 and E.U.-15, Economic Research-Ekonomska Istraživanja, 32:1, 2699-2722

Anon., 2016. What Is the Bioeconomy? A Review of the Literature 691. Sustainability .

Bio-based Industries Consortium 2018 Mapping the potential of Poland for the bio-based industry

Bio-based Industries Consortium 2018 Mapping the potential of Romania for the bio-based industry

BIOEAST - https://bioeast.eu/home/ , 16 Feb, 2020

Brizga J.,2019, The challenges of bioeconomy implementation consideringenvironmental aspects in the baltic states:an input-output approach, International Conference "ECONOMIC SCIENCE FOR RURAL DEVELOPMENT" No 52, 355-362

de Besi M., McCormick K., Towards a Bioeconomy in Europe: National, Regional and Industrial Strategies, Sustainability 2015, 7, 10461-10478

Dupont-Inglis, Joanna, Borg, Agnes, 2018, Destination bioeconomy - the path towards a smarter, more sustainable future. New Biotechnology

European Commission, A sustainable Bioeconomy for Europe: strengthening the connection between economy, society and the environment, Brusseles, 2018.

European Commission, Innovating for Sustainable Growth - A Bioeconomy for Europe Luxembourg: Publications Office of the European Union, 2012.

Georgescu-Roegen, N., 1971. The entropy law and the economic process. Cambridge (USA):Harvard University Press.

Georgescu-Roegen, N., 1977. Inequality, limits and growth from a bio-economic viewpoint. Review of Social Economy 361-375.UN, 2015

Hänninen, R. et al., 2018. Complexity of Assessing Future Forest Bioenergy Markets—Review of Bioenergy Potential Estimates in the European Union. Current Forestry Reports, 4(1), pp. 13-22.

Imbert, E., Energy Research \& Social Science (2017) 
Juhász, A., Vásáry, V., 2017. "BioEast: Central-Eastern European initiative for knowledge-based agriculture, aquaculture and forestry in the bioeconomy," Rural Areas and Development, European Rural Development Network (ERDN), vol. 14, pages 1-18.

Lewandowski I - 2015, Bioeconomy Shaping the Transition to a Sustainable, Biobased Economy McCormick K, Kautto N, 2013, The Bioeconomy in Europe: An Overview, Sustainability 2013, $5,2589-2608$

PICBE $\mid 90$

OECD (2009), The Bioeconomy to 2030: Designing a Policy Agenda, OECD Publishing, Paris.

Rizos, et al. 2018, The Role of Business in the Circular Economy: Markets, Processes and Enabling Policies.

Rodriguez-Anton, et al., 2019. Analysis of the relations between circular economy and sustainable development goals. International, Journal of Sustainable Development \& World Ecology.Ronzon et al., 2015, p. 4

Ronzon, T. and R. M'Barek (2018). "Socioeconomic Indicators to Monitor the EU's Bioeconomy in Transition." Sustainability 10(6): 1745

Scarlat, N., et al., The role of biomass and bioenergy in a future bioeconomy: Policies and facts. Environmental Development (2015)

Vásáry, V., \& Szabó, D. (2018). Characteristics of Sustainable Bioeconomy in the CEE Macroregion. Central European Review of Economics \& Finance, 27(5), 5-26. 